DOI: 10.32481/djph.2021.07.011

\title{
Beyond COVID-19:
}

\section{Technology and Connectivity Help Bridge the Divide in Equitable Care}

\author{
Sharon Anderson, RN, BSN, MS, FACHE \\ Chief Virtual Health Officer, ChristianaCare \\ During the COVID-19 pandemic, virtual care delivery increased exponentially. As we \\ continue to advance this model of care, it will be critical to address issues of access to \\ technology with a specific focus on access to the broadband needed to support virtual \\ care delivery. Without addressing these issues, the digital divide will widen and prevent \\ equitable access to quality health care.
}

Virtual care grew rapidly during the COVID-19 pandemic, with a $120 \%$ increase documented between March 2020 and May 2021 at ChristianaCare alone.

As ChristianaCare is committed to the delivery of equitable, quality health care, focused effort was placed on ensuring access to virtual care for all. A grant from the Federal Communications Commission (FCC) under the COVID-19 CARES Act awarded in April 2020 is helping ChristianaCare increase broadband access to telehealth services for vulnerable and underserved Delawareans. ChristianaCare is utilizing the funds received to connect 7,500 marginalized patients to telehealth with smart phone devices and data plans. It is also supporting the establishment of on-site telehealth services in communities with high disease burden and challenges accessing virtual health services.

\section{Addressing Social Determinants of Health for Equitable Access}

As the COVID-19 pandemic swept through the State of Delaware, ChristianaCare cared for approximately two-thirds of all COVID-19 positive Delawareans who required hospitalization or ambulatory care. Early in the pandemic, Delaware experienced a statewide increase from 56 to 783 COVID-19 cases over the 14-day period between March 22 and April 6, 2020. ${ }^{1}$ During the same 14-day period, ChristianaCare alone experienced an increase from 35 to 490 COVID-positive cases. Of those, 89 patients required hospitalization and intensive therapy.

Early data suggested that Delawareans in traditionally underserved medical communities were also disproportionately more likely to contract COVID- $19 .{ }^{2}$ For those individuals aged $\geq 18$ years who received testing at ChristianaCare during this 14-day period, nonHispanic Black patients were two times more likely to be COVID-19 positive compared with their White counterparts (16\% (213/1353) vs. 7\% (206/1901), respectively).

The disparity in positivity rate for COVID-19 is thought to have largely been driven by variation in social determinants of health, that is the conditions in the environment where people live, learn, work and play. ${ }^{3}$ The social determinants of health impact wellness and care. The divide has never been more evident than during the pandemic when a significant portion of in-person ambulatory care transitioned to virtual for longitudinal outpatient monitoring and care to prevent a rise in acute care utilization. 


\section{Pivoting Quickly to Care for Our Community}

In March 2020, to reduce the need for in-person visits for patients with suspected COVID-19, ChristianaCare accelerated the capabilities of an already existing robust digital transformation plan by several years. The plans already in place for virtual care made it possible to quickly pivot and remotely monitor and care for those with COVID19 , and to safely support patients with chronic health care needs.

ChristianaCare developed a screening algorithm to identify the population who called for primary care and specialty practice visits who were suspected of having COVID-19 (figure 1). These patients were immediately referred to ChristianaCare's COVID-19 Virtual Practice for a telemedicine visit and triage (figure 2).

Figure 1. COVID-19 Telehealth Monitoring Workflows

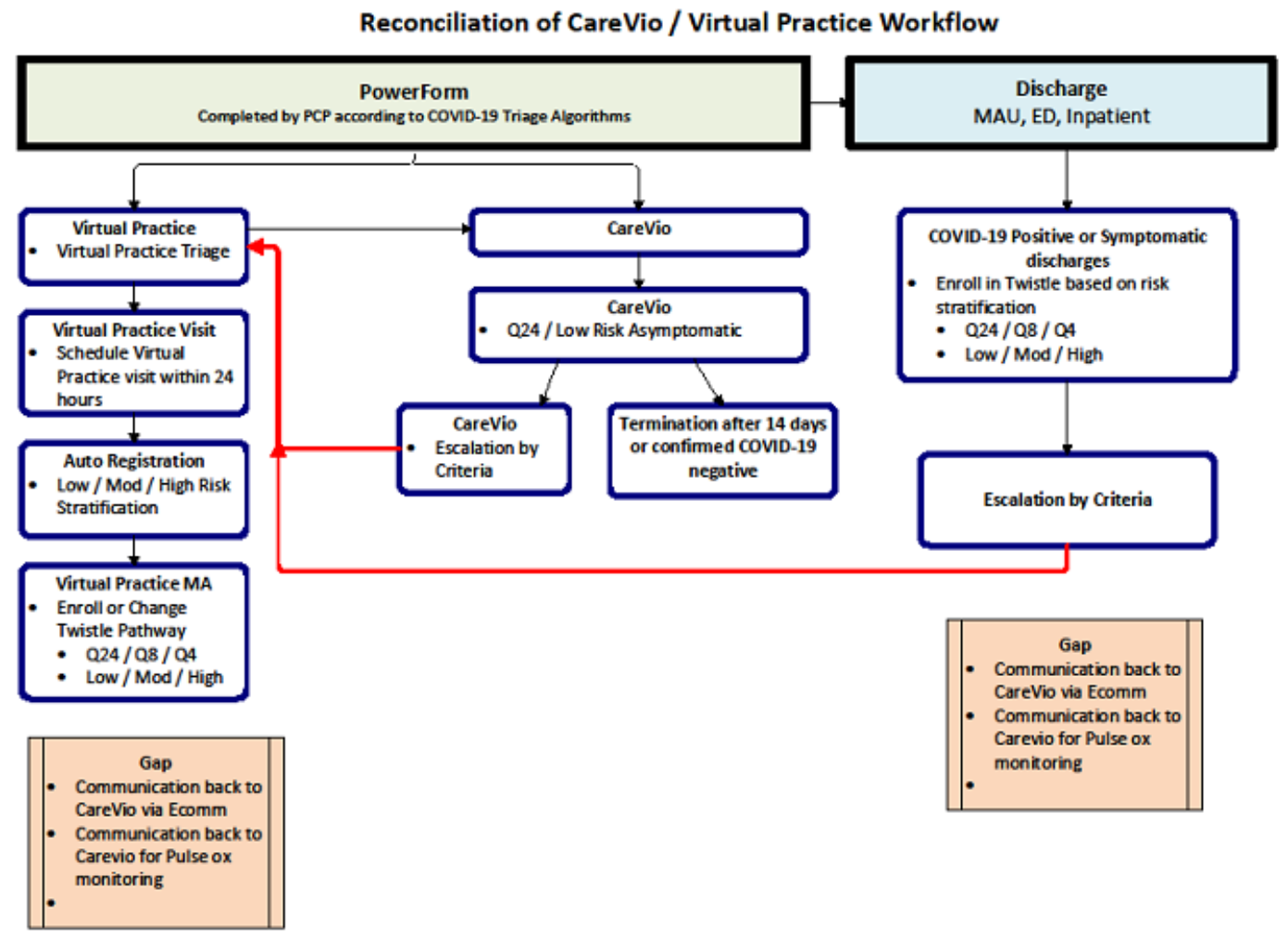

Figure 2. Severity-based Triage Criteria for Monitoring Frequency 


\begin{tabular}{|c|c|c|c|c|}
\hline $\begin{array}{c}\text { Criteria for COVID-19 } \\
\text { Monitoring }\end{array}$ & $\begin{array}{c}\text { Low Risk } \\
\text { Q24 Monitoring }\end{array}$ & $\begin{array}{l}\text { Moderate Risk } \\
\text { Q8 Monitoring }\end{array}$ & $\begin{array}{l}\text { High Risk } \\
\text { Q4 Monitoring }\end{array}$ & $\begin{array}{l}\text { Who Gets a } \\
\text { Pulse 0x }\end{array}$ \\
\hline Pulse Rate & $<90$ & $\begin{array}{l}\geq 90-100 \\
\text { or } \\
\geq 50-59\end{array}$ & $\begin{array}{l}>101 \\
\text { or } \\
<50\end{array}$ & \multirow{6}{*}{ 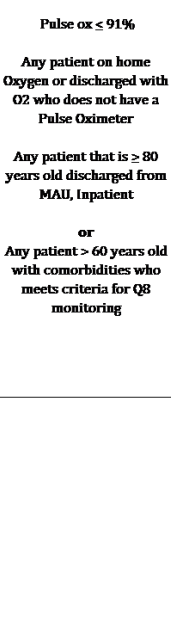 } \\
\hline Breathing Rate & $<21$ & $\geq 21-24$ & $\geq 25$ & \\
\hline Temperature & \begin{tabular}{|l}
$\geq 97-99.5$ in persons $>65$ \\
$\geq 97-99.5$ in persons $<65$ years w/comorbid \\
conditions" \\
$\geq 97-1003$ in persons $<6.5$ \\
$\geq 97$ \\
\end{tabular} & $\begin{array}{l}\geq 99.6-101.5 \text { in persons }>65 \text { years } \\
\geq 99.6-101.5 \text { in persons }<65 \text { years with comorbid } \\
\text { condions" } \\
\geq 101.6 \text { in persons }<65 \text { years }\end{array}$ & $>102$ & \\
\hline Pulse ox if available & $\geq 92 \%$ & $\geq 92 \%$ & $\leq 91 \%$ & \\
\hline $\begin{array}{l}\text { Risk Stratification } \\
\text { Score (Guide) }\end{array}$ & & $\begin{array}{l}\text { Any patient with a risk stratification score } \geq 8 \\
\text { Any patient }>60 \mathrm{y} / \mathrm{o} \text { with comortid conditions and } \mathrm{a} \text { risk } \\
\text { stratification score } \geq 6\end{array}$ & $\begin{array}{l}\text { Any patient with a risk stratification } \\
\text { score } \geq 10 \\
\text { Any patient }>60 \text { y/o with comorbid conditions } \\
\text { and a risk stratification score } \geq 8\end{array}$ & \\
\hline $\begin{array}{l}\text { Comorbid Conditions* } \\
\text { Heart Disease } \\
\text { Diabetes } \\
\text { Chronic Lung Disease } \\
\text { Active Cancer } \\
\text { Neurologic Disease } \\
\text { Immunodepression }\end{array}$ & $\begin{array}{l}\text { Escalation Griteria: } \\
\text { Worsening symptoms : } \\
\text { Harder to breathe } \\
\text { Feeling sicker } \\
\text { Pulse Rate: } \geq 90 \\
\text { Breathing Rate: } \geq 21 \\
\text { Temperature: Worsening Fever } \\
\text { New onset of other illness [ies severe abdominal pain, } \\
\text { diarntea w/dehydration, uncontrollable headachej. }\end{array}$ & $\begin{array}{l}\text { Or deemed necessary secondary to VP provider clinical } \\
\text { decision making after Virtual visit }\end{array}$ & $\begin{array}{l}\text { Or deemed necessary secondary to } \\
\text { VP provider clinical decision making after } \\
\text { Virtual visit }\end{array}$ & \\
\hline
\end{tabular}

Through ChristianaCare's COVID-19 Virtual Practice, ${ }^{4}$ patients were evaluated for the need for testing, tested, and subsequently enrolled in a HIPAA-secure texting COVID-19 monitoring system for daily assessment. Powered by ChristianaCare's CareVio ${ }^{\mathrm{TM}}$ care management service, the virtual COVID-19 practice used secure texting to check in with patients daily, create a risk score, elevate people who have a change in their status to a virtual visit, and then intervene to provide them with additional technology, another virtual provider visit or provide additional services in the home or bring them in for inperson care. When possible, caregivers used telehealth to review the cases of hospitalized patients.

An internal algorithm calculates the patient's severity score and triggers care management intervention. The ChristianaCare Center for Virtual Health created a dashboard to monitor the COVID-19 population (figure 3).

Figure 3. The ChristianaCare Center for Virtual Health Dashboard to Monitor the COVID-19 Population. 
DOI: $10.32481 / \mathrm{djph} .2021 .07 .011$
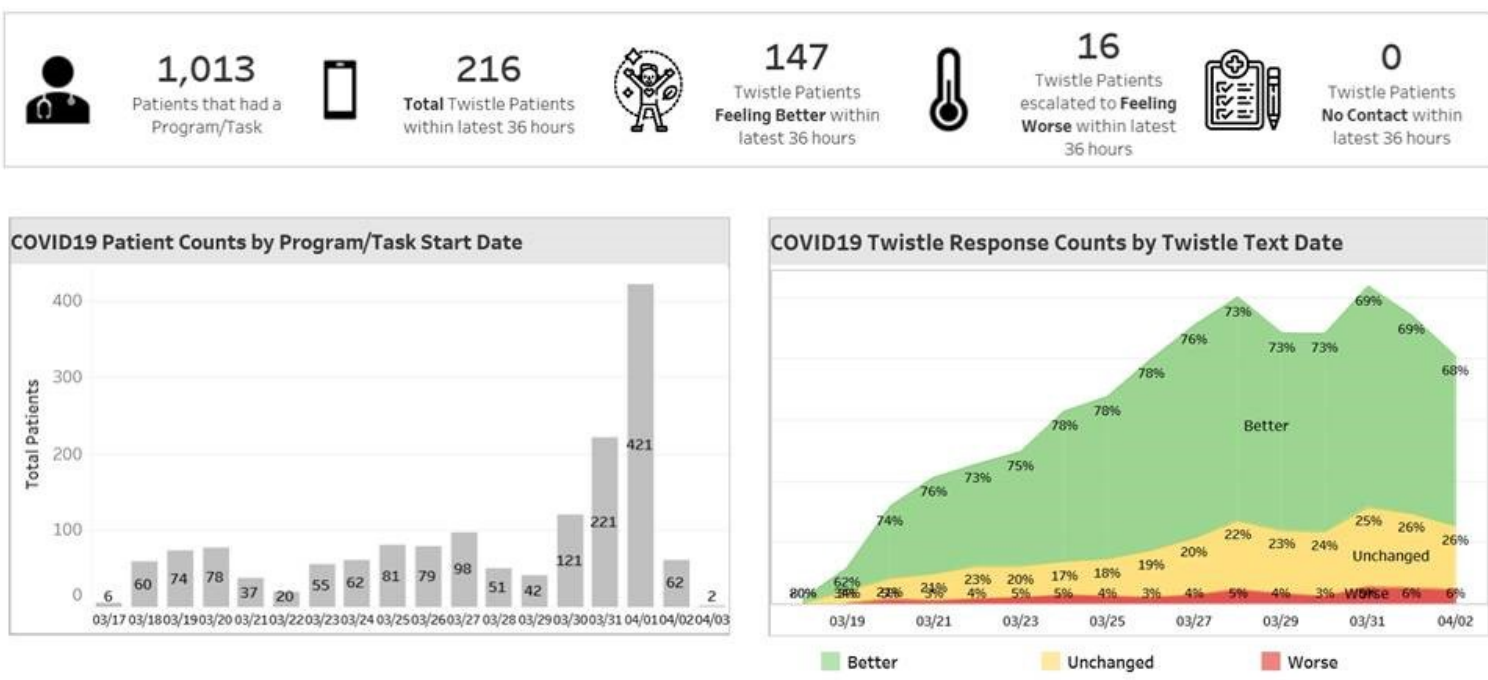

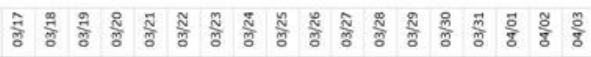

Patients

Patients
Enrolled/Tasked

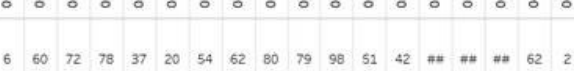

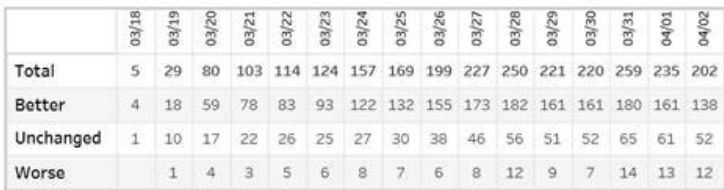

\section{Mitigating Risks for Patients and Caregivers}

In November 2018, ChristianaCare launched a primary care virtual practice allowing employees, spouses and dependents to self-schedule telehealth video appointments and connect with their primary care team through secure, electronic messaging. The foresight of establishing this practice allowed the system to quickly pivot and continue to provide care during the pandemic.

To mitigate risks of exposure to COVID-19 for both patients and caregivers, in a matter of weeks, ChristianaCare built on the success of its virtual employee practice to shift all primary and ambulatory patient care to video or phone visits.

To safely screen and support those who tested positive for COVID-19, who had significant exposure, or who worked in high-risk professions, ChristianaCare was then able to establish two COVID-19-focused ambulatory care centers.

With this shift, telehealth utilization increased. Telehealth visits comprised $7 \%$ of ChristianaCare ambulatory care visits between July - September 2020. That number soared to 74\% between October and December 2020. Between January and March 2021, nearly half (44\%) of ambulatory care visits remained virtual.

In spring 2020, ChristianaCare also launched an Employer COVID-19 Symptom Monitoring Program to provide daily monitoring of employees for COVID-19 symptoms, testing, if needed, and care for those who test positive. Also powered by CareVio, this program increased safety and eased anxiety in the workplace for more than 10,000 employees from 37 companies in 14 states. 
Between March 2020 and May 2021, ChristianaCare's COVID-19 Virtual Practice conducted nearly more than 183,000 virtual visits in four touch areas with more than 2,000 patients (figures $4 \& 5$ ).

- Synchronous Virtual Care - Video visits increased by $98 \%$ to more than 11,200 from a baseline of fewer than 4,800.

- Asynchronous Communication - Bi-directional, secure text messaging increased to more than 121,600 messages, and patient portal messages increased to more than 40,000 per month.

- Virtual Consults - Clinician use of the internal referral and Cerner's eComm increased by 43\% to 964 in March 2021 from an average of 504 in FY 2020.

- Digital Frictionless Experience - patient portal activity, portal enrollment, eClipboard attachments and direct book appointments increased by $37 \%$, with portal activity and portal enrollment accounting for highest volumes of touches.

Figure 4. Between March 2020 and May 2021, ChristianaCare's COVID-19 Virtual Practice conducted nearly 200,000 virtual visits with more than 2,000 patients. 


\section{Virtual Patient Visits}

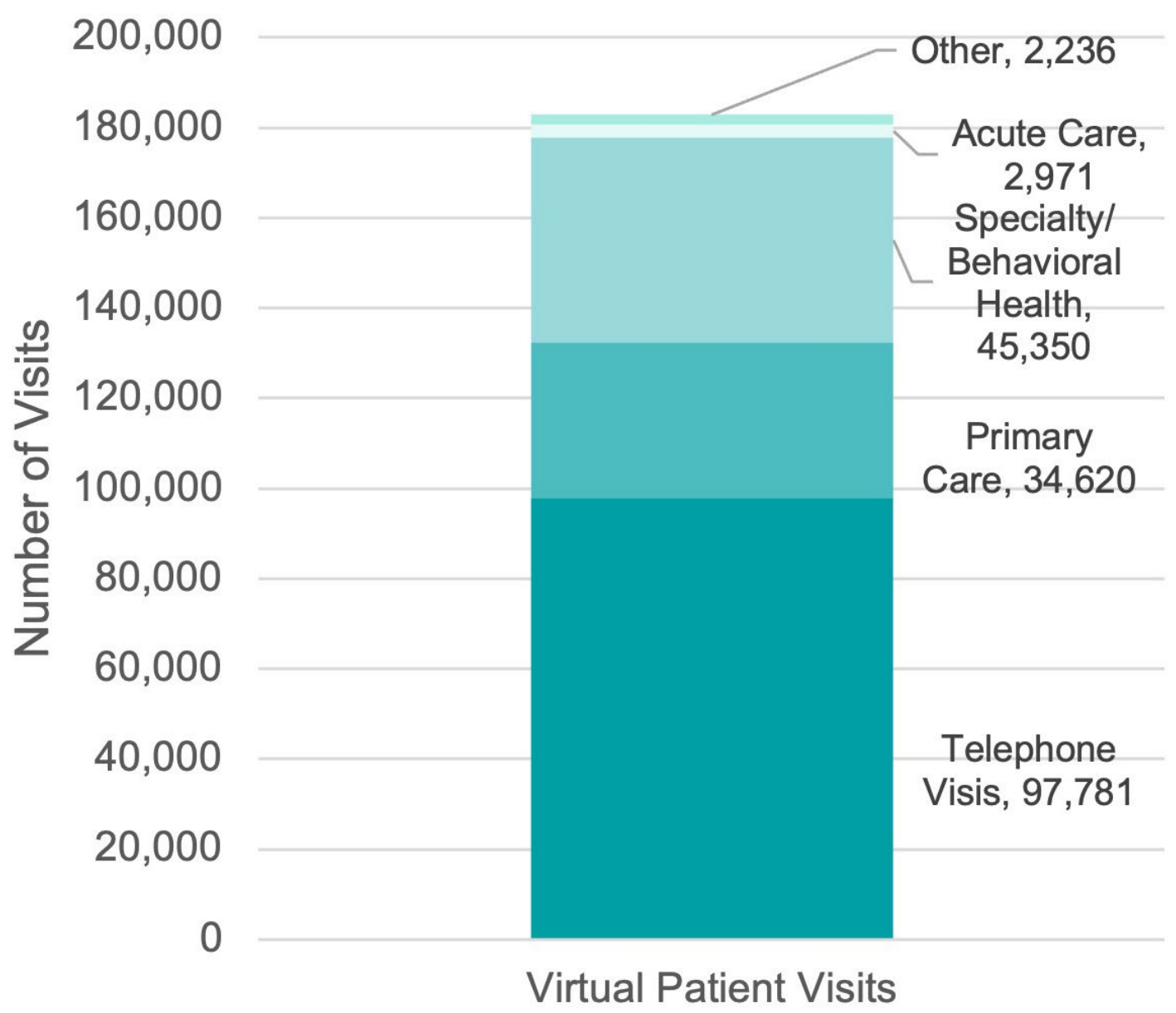

Figure 5. The four "touches" of virtual care increased more than 120\% during FY 2021. 


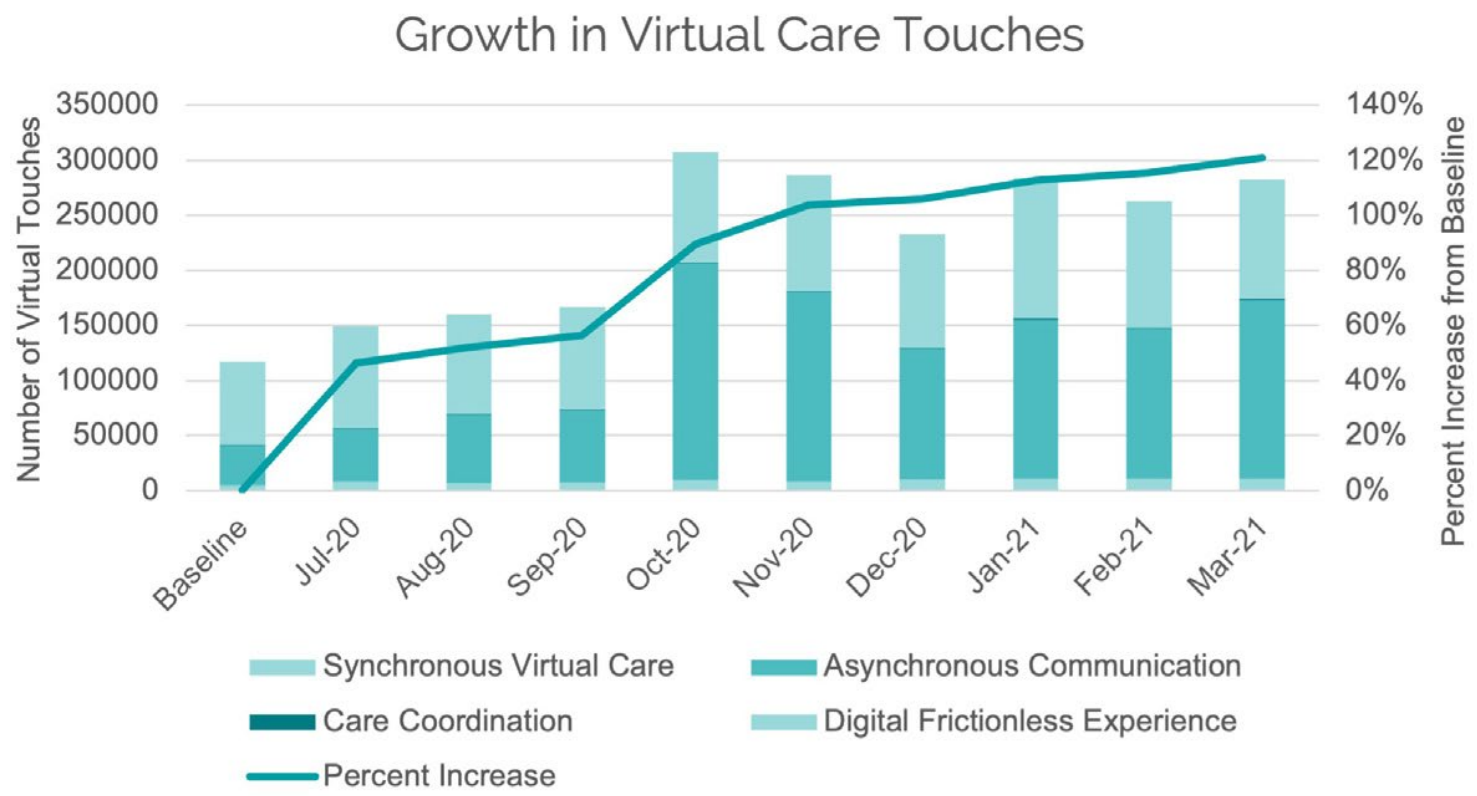

Predictive modeling reported in April 2020 by ChristianaCare's Institute for Research on Equity and Community Health (iREACH) in collaboration with the University of Delaware (UD) and the Delaware Emergency Management Agency (DEMA), pointed to an estimated 80,000 individuals who would require ambulatory care before the pandemic's end. In June of 2021 as we approach the tail end of the pandemic, more than 100,000 Delawareans have tested positive for COVID-19 requiring some level of ambulatory care.

\section{Expanding Virtual Services}

ChristianaCare's experience in managing more than 1,700 patients in the Center for Virtual Health COVID-19 telehealth monitoring program led us to conclude that we could expand our virtual services to include a broader scope of offerings and an increased volume.

Yet an estimated $20 \%$ of Delaware's population lacks broadband internet access. In some communities in the cities of Wilmington and Dover, and in some more rural areas in the southwestern part of the state, more than $50 \%$ of the population is without broadband internet access. And across the State, limited broadband internet access is correlated with both, socio-economic vulnerability as well as density of race/ethnic minority populations (Figure 6).

Figure 6. Delaware demographics, including broadband internet access 


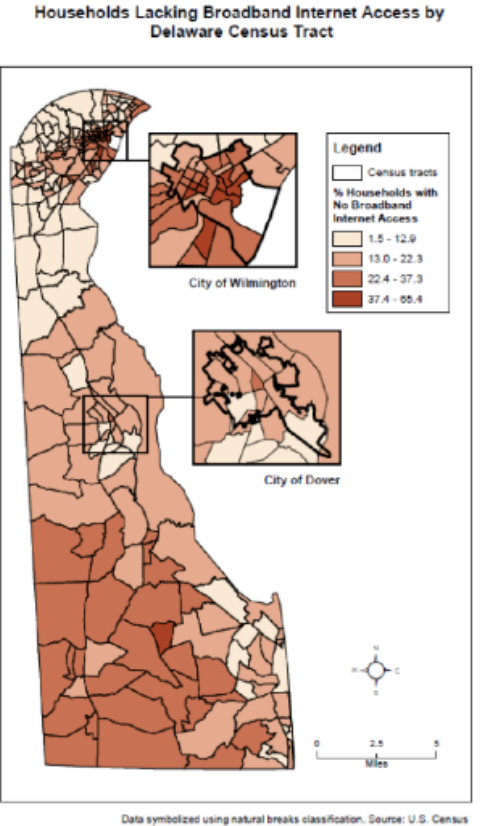

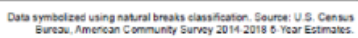
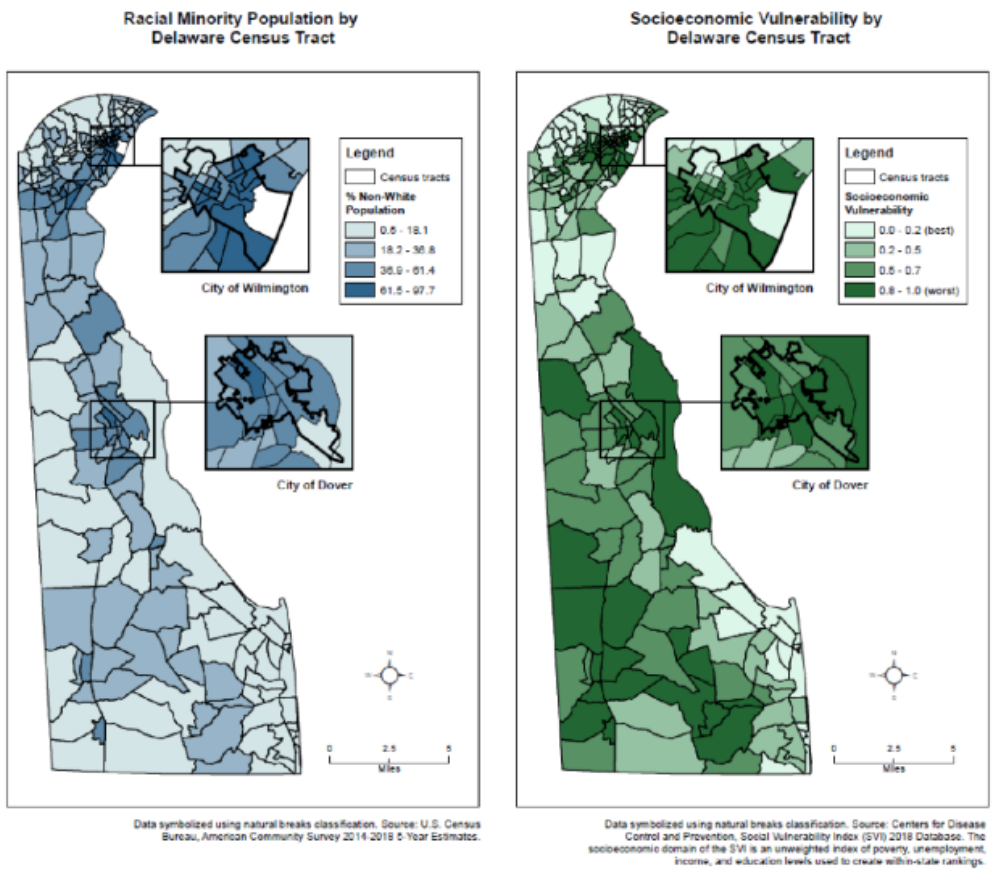

The disproportionate number of potentially positive high-risk community members who reside in communities with poor broadband access (Figure 7) made improving our ability to provide virtual care to all ambulatory COVID-19 cases critically important.

Figure 7. Confirmed cases of COVID-19 by ZIP code.

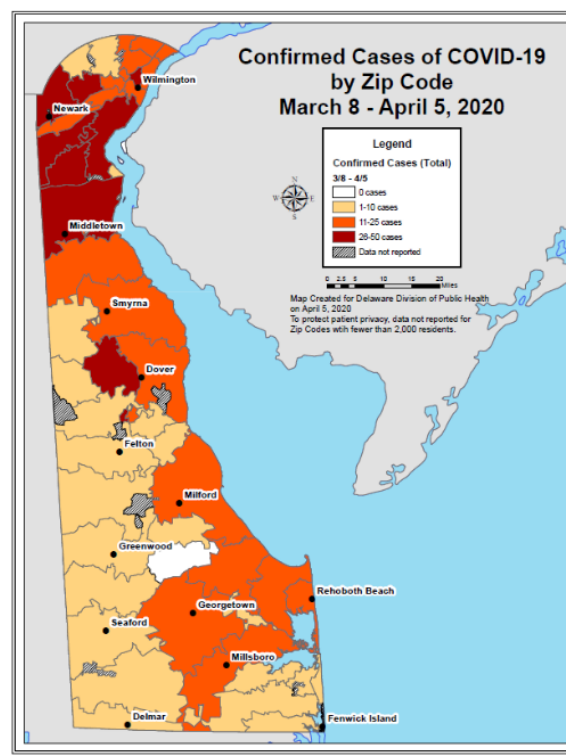

The majority of ChristianaCare patients are from New Castle County, Delaware, where there is substantial variation in socioeconomic conditions. Of 162,000 Delawareans who live within five New Castle County ZIP codes (19801, 19802, 19804, 19805 and 19720), approximately $20 \%$ live in poverty (a number higher than the national average), according to a recent iREACH investigation. About $56 \%$ of households in these ZIP codes are "rent burdened," spending more than $30 \%$ of their household income on rent. These significant financial strains further translate to lack of broadband connectivity. 
Delaware's Department of Technology and Information has made tremendous progress in the elimination of broadband deserts in Delaware. Through private sector partnerships, Delaware has been able to greatly increase its fiber optic and cellular tower footprint. ${ }^{5,6}$ Therefore, most of the lack of access to broadband can be attributed to the high cost of devices and monthly fees for data plans.

With funds from the FCC grant, ChristianaCare is providing smartphones to patients enrolled in ChristianaCare's COVID-19 monitoring program. The devices are configured to allow 911 calls, video visits through ChristianaCare's telehealth platform, and HIPAAsecure text-messaging with health care providers. They may also be configured with Bluetooth-enabled pulse oximetry monitors and the MEDPOD telediagnostic suite of applications - including sphygmomanometer, scale, thermometer, EKG, spirometer, pulse oximeter and glucometer - for diagnostic intervention and/or in-home consultation.

On-site community-based access points equipped with devices necessary for telehealth services and/or connectivity services allow us to engage with community partners to get care to the community when, where and how people need or are willing to receive it. Options such as technology kiosks located in Delaware libraries or Community Access Points staffed with a nurse and a patient digital ambassador connect patients to primary care providers, behavioral health specialists or pharmacists. These Community Access Points, such as the one located at the Kingswood Community Center, provide access to virtual care that overcomes barriers including transportation, lack of child care, or limited time off from work..

\section{The New Venue of Care is Home, or Wherever the Patient Is}

People will often reach out for help for urgent care concerns - things like low back pain or sinus infections - but wellness tends to take a back burner for busy or stressed patients, particularly those from vulnerable communities. Virtual care is a promising avenue to help us transition from a culture of seeing a primary care doctor once a year with a long list of questions to a place of convenient access through synchronous and asynchronous communication that longitudinally supports patients in getting the care they need when they need it. We now know that care doesn't have to happen within the four walls of an exam room. It can happen "virtually" anywhere.

And coupling care delivery with research allows us to utilize the data generated from our clinical work in underserved communities, continue to examine demographic and clinical characteristics, and understand how broadband telehealth impacts marginalized populations as we work to bridge the divide in access to care.

\section{Whatever Can, Will}

The transition to virtual health goes beyond simply replacing in-person doctor visits with video visits. It calls on providers and health systems to reimagine and recreate the entire experience of care. Recognizing that the future of health care is virtual, and the new venue of care is home, ChristianaCare has committed to ensuring that whatever can be done virtually will be done virtually. 
In the world of virtual health, care no longer revolves around an appointment with a provider. Rather, it's proactive, coordinated and continuous. It requires looking at ways to provide the right care at the right time by the right health professional; reduce emergency and urgent care visits, and lower the cost of care to a fraction of the cost of traditional care delivery models.

- Through telephone, video, and secure, HIPAA-compliant, bi-directional texting, email or wearable devices, virtual health is also taking care management to the next level. Population health allows providers to study populations of patients and know who among them is at greatest risk, who is vulnerable, and who needs additional support.

- Virtual health brings more and more care to the home in ways that are accessible and radically convenient for patients and their loved ones. This new, fully personalized virtual care model engages people with health care experts and allows patients to form stronger connections to their health care team about the things that matter most, without waiting for the next traditional office visit.

- Virtual care allows providers to connect with people at the right time, and with the information that encourages them to be more involved in their own wellness journey, and creates a more integrated, continuous feedback loop.

- Perhaps most importantly, virtual care continues when people are still well, providing self-service access and proactive reminders to preclude unnecessary hospital admissions and readmissions and achieve optimal health outcomes.

\section{Care That Doesn't Pause Between Visits}

As we look to the future of virtual health, the opportunities are as varied as our patients' needs. ChristianaCare is moving forward with telehealth rounds for inpatient care and virtual specialty care and disease specific programs.

We have introduced telemonitoring for in-home care of patients with heart failure by ChristianaCare HomeHealth; an Alexa Skill Home Care Coach ${ }^{\mathrm{TM}}$ for customized prompts to patient questions; and a free mobile pregnancy app to help moms-to-be monitor their health, track their baby's growth and prepare for baby's arrival.

We've even started to imagine a hospital at home, where acute care patients can stay in their home to receive care resulting in improved outcomes at a lower cost for the patient all at the same level and quality of care as an in-hospital stay.

It's important to note that we are not replacing in-person care options with virtual care. We are providing choices. We're reaching people who want their care at home, who can't - or won't - come in person, or those who would clinically be better cared for in a different setting. And we are conducting research alongside our care delivery to make sure we are evaluating the impact of everything we do, building in a health equity lens to ensure we are closing the health disparity gap. 
DOI: 10.32481/djph.2021.07.011

Our model is an interdisciplinary team that delivers longitudinal care in a radically different way that breaks the model of how we have traditionally thought about health care. The old ways of in-person, facility-based care aren't obsolete. But the new ways show tremendous progress for improving outcomes and both patient and provider experience.

What's so powerful about virtual care is that it doesn't pause between visits; it's continuous. By embracing data and technology — and by providing telehealth services to vulnerable patients and neighborhoods that lack broadband connectivity - we are building a telemedicine foundation to address disparities in access to care that extends well beyond COVID-19.

\section{References}

1. State of Delaware. (n.d.). MyHealthyCommunity; COVID-19 Overview. Retrieved from: https://myhealthycommunity.dhss.delaware.gov/locations/state

2. The Beacon. (2020, Oct 5). DSU awarded \$1.5M grant to study COVID-19 in underserved communities. The Beacon.

https://www.milfordbeacon.com/story/news/2020/10/05/dsu-awarded-1-5-m-grantstudy-covid-19-underserved-communities/3631400001/

3. Orgera, K., Garfield, R., \& Rudowitz, R. (2021, Jun 9). Implications of COVID-19 for social determinants of health. The Kaiser Family Foundation. https://www.kff.org/coronavirus-covid-19/issue-brief/implications-of-covid-19-forsocial-determinants-of-health/

4. ChristianaCare. (n.d.). Virtual care. https://christianacare.org/virtual-primary-care/

5. Governor John Carney. (2019, May 31). Governor Carney, DTI announce rural broadband expansion partnership. Office of the Governor. https://news.delaware.gov/2019/05/31/governor-carney-dti-announce-ruralbroadband-expansion-partnership/

6. Governor John Carney. (2020, Aug 24). Governor Carney announces \$20 million for broadband infrastructure. Office of the Governor. https://news.delaware.gov/2020/08/24/governor-carney-announces-20-million-forbroadband-infrastructure/

Copyright (c) 2021 Delaware Academy of Medicine / Delaware Public Health Association.

This is an Open Access article distributed under the terms of the Creative Commons Attribution NonCommercial License (https:/creativecommons.org/licenses/by-nc-nd/4.0/) which permits unrestricted noncommercial use, distribution, and reproduction in any medium, provided the original work is properly cited. 